\title{
Study of the Correlation between Helicobacter pylori Infection and Hepatic Encephalopathy in Patients with Liver Cirrhosis
}

\author{
Atef Abo El Soud Ali ${ }^{1}$, Hosam El Din Mostafa Seleem ${ }^{1}$, \\ Abeer Hamdy EI Shalakany ${ }^{2}$, Mahmoud Farouk Kamel ${ }^{3}$ \\ ${ }^{1}$ Tropical Medicine Department, Faculty of Medicine, Menofia University, Egypt \\ ${ }^{2}$ Clinical Pathology Department, Faculty of Medicine, Menofia University, Egypt \\ ${ }^{3}$ Menshyet Elbakry General Hospital, Cairo, Egypt
}

Corresponding Author Mahmoud Farouk Kamel

Mobile:

01002818618

E mail:

abo_nabil30@yahoo.c om.

Key words:

H.pylori, Hepatic encephalopathy, ELISA, Liver cirrhosis
Background and study aim: Ammonia plays a major role in hepatic encephalopathy pathogenesis. Most of ammonia is known to be produced by the action of colonic bacteria which possess a urease enzyme activity. $H$. pylori which infects the stomach possesses a stronger urease activity which produce a large amount of ammonia that may precipitate hepatic encephalopathy (HE). The aim of the present study is to determine the correlation between Helicobacter pylori infection and $\mathrm{HE}$ in patients with liver cirrhosis.

Patients and Methods: One hundred patients (50 patients of liver cirrhosis with hepatic encephalopathy and 50 patients of liver cirrhosis without hepatic encephalopathy) were evaluated for presence of $H$. pylori by stool antigen test (ELISA method) and for blood ammonia level estimation. Results: Pevalence of $H$. pylori infection in the study groups (patients of liver cirrhosis with and without hepatic encephalopathy) was $70 \%$ (liver cirrhosis with hepatic encephalopathy group (A) $80 \%$, and liver cirrhosis without hepatic encephalopathy group (B) 60\%). Mean blood ammonia levels were: $82.14 \pm 47.9$ $\mathrm{mmol} / \mathrm{l}$ for group A (liver cirrhosis with hepatic encephalopathy) and 36.44 17.9 $\mathrm{mmol} / \mathrm{l}$ for group B (liver cirrhosis without hepatic encephalopathy). Prevalence of $H$. pylori and blood ammonia level were found significantly increasing with the severity and the degree of hepatic encephalopathy. Conclusion: There is a significant association between $H$. pylori and hepatic encephalopathy in patients with liver cirrhosis. There may be a role of anti- $H$. pylori therapy in patients of hepatic encephalopathy and should be investigated further.

\section{INTRODUCTION}

Hepatic encephalopathy (HE) is a dangerous complication affecting patients with liver cirrhosis. The reversible nature of this neuropsychiatric syndrome with its widespread cerebral changes suggests a metabolic mechanism. The brain is exposed to several neuroactive toxins, in particular ammonia, due to failed hepatic clearance or the abnormal peripheral mechanisms of the cirrhotic [1]. So ammonia plays a key role in $\mathrm{HE}$ and even the more recent theories that involve other agents also incorporate an increased ammonia level as an exacerbation factor [2]. Although kidney and muscle may liberate ammonia, most is of gut origin produced by action of bacterial flora on dietary protein and on epithelial and bacterial debris. Normally ammonia is extracted by the liver where it is used for synthesis of urea. In cirrhotics however, large quantities of ammonia reach the systemic circulation because of portal systemic shunting and impaired urea synthesis [3]. Bacterial urease enzyme contributes significantly to absorbed ammonia as a result of daily hydrolysis of $15-30 \%$ of total body urea [4]. Although this activity is usually attributed to faecal bacteria, the stomach, which possesses strong activity when infected with Helicobacter pylori, is considered as an alternative site. $H$. pylori are known to produce copious amounts of ammonia due to its strong urease activity many times greater than that of urease positive enterobacteria. 
Urea readily diffuses from blood into the gastric lumen where, in the presence of H.pylori is hydrolyzed to ammonia leading to a rise in arterial levels in $50 \%$ of normal subjects and in virtually all cirrhotics [5]. It has been shown that the ammonia concentrations in portal and venous blood significantly increased after the instillation of $1 \mathrm{ml} 10^{7}$ colony forming units $(\mathrm{CFU}) / \mathrm{ml}$ of $\mathrm{H}$. Pylori in the stomach of cirrhotic rats, suggesting that the ammonia produced by $H$. pylori has a role in the pathogenesis of hyperammonaemia when this organism is widely distributed and is present in large numbers in the stomach, particularly in the presence of liver cirrhosis [6]. Blood ammonia levels were found to be higher in cirrhotic patients with $H$. pylori infection than in uninfected patients in some studies [7].

This finding was supported by some therapeutic trials on the effect of $H$. pylori eradication therapy on hyperammonaemia in patients with liver cirrhosis [8].

\section{PATIENTS AND METHODS}

The present study was conducted on one hundred patients (50 patients with liver cirrhosis and hepatic encephalopathy and 50 patients with liver cirrhosis without hepatic encephalopathy).

They were choosen after taking written consent from out-patient clinic and in-patient department in Helwan Fever Hospital during the period from November 2013 to June 2014.

The patients were divided into two groups:

Group (A): Hepatic encephalopathy group comprised of 50 patients (30 males and 20 females) with age range from 44 to 69 years with a mean age $56.24 \pm 8.91$

Group (B): Non- hepatic encephalopathy group containing 50 patients $(28$ males and 22 females) with age range from 39 to 64 years with a mean age $45.56 \pm 11.72$.

All patients (with and without hepatic encephalopathy) were subjected to the following:

- Full history taking.

- Clinical examination with special stress on presence of stigmata of liver cirrhosis.

- Abdominal ultrasound.

- Laboratory investigations:

- Liver biochemical profile: namely total bilirubin, direct bilirubin, alanine transaminase
(ALT), aspartate transaminase (AST), albumin, prothrombin time and concentration [9].

- Arterial blood ammonia estimation [10].

- Stool antigen test based on ELISA technique (enzyme linked immunosorbent assay) to detect H.pylori antigens [11].

\section{Statistical analysis:}

All patients/ data were tabulated and processed by SPSS 12.0 statistical package for Windows xp.

\section{Descriptive data:}

Descriptive statistics were calculated in the form of: Mean, Standard deviation $( \pm S D)$, minimum and maximum and frequency (No-\%).

\section{Analytical statistics:}

- Quantitative variables were expressed by mean \pm standard deviation (SD) and analyzed by ANOVA test.

- Spearman correlation was used to correlate different grades of $\mathrm{HE}$ with laboratory variables.

- Qualitative variables were expressed by number and percent and analysed by Chi-square test.

- In all test, P value was considered significant when less than 0.05 .

\section{RESULTS}

Results of the present study can be summarized in the following:

- Manifestations (symptoms and signs) of liver cirrhosis were present in the two groups of the study.

- All grades of hepatic encephalopathy were represented in hepatic encephalopathy group (A).

- As regarding symptoms halitosis and heart burn were significantly higher in hepatic encephalopathy group (A) than non-hepatic encephalopathy group (B).

- On the other hand, there was no significant difference between the studied groups as regard dyspepsia, abdominal distension, nausea, vomiting, abdominal pain and dysphagia.

- As regarding signs there is no significant difference between the studied groups.

- Ultrasonographic features of cirrhosis were present in the two studied groups with no significant difference between them.

- The mean values of serum T. Bilirubin in group (A) were significantly higher than that of group (B).

- There were no significant difference between ALT mean values in the studied groups. 
- There were no significant differences between AST mean values in the studied groups.

- There were no significant differences between albumin mean values in the studied groups.

- There were no significant differences between prothrombin concentration mean values in the studied groups.

- Prevalence of $H$. pylori infection was significantly higher in group (A) than in group (B).
- Prevalence of $H$. pylori infection was significantly increasing with increasing the grade and severity of hepatic encephalopathy in group (A).

- The mean ammonia levels were significantly higher in group (A) than group (B).

- The mean ammonia levels were significantly rising with increasing the grade and severity of hepatic encephalopathy in group (A).

Table (1): Hepatic encephalopathy grading in group A (HE group) of the study

\begin{tabular}{|c|c|c|}
\hline \multirow{2}{*}{ HE Grade } & \multicolumn{2}{|c|}{ HE group } \\
\cline { 2 - 3 } & $\mathrm{N}$ & $\%$ \\
\hline Grade I & 14 & 28 \\
\hline Grade II & 14 & 28 \\
\hline Grade III & 12 & 24 \\
\hline Grade IV & 10 & 20 \\
\hline Total & 50 & 100 \\
\hline
\end{tabular}

Analysis of the studied hepatic encephalopathy group revealed a 14(28\%) of the patients were grade I hepatic encephalopathy, 14(28\%) of the patients were grade II hepatic encephalopathy, 12(24\%) of the patients were grade III hepatic encephalopathy and 10(20\%) of the patients were grade IV hepatic encephalopathy.

Table (2): Clinical picture: (Symptoms) of the studied groups

\begin{tabular}{|c|c|c|c|c|c|}
\hline \multirow{2}{*}{ Item } & HE $\operatorname{group}(A)$ & Non-HE group (B) & \multicolumn{2}{|c|}{ Total } & \multirow{2}{*}{ P. Value } \\
\hline & $\mathrm{N}=50 \quad \%$ & $\mathrm{~N}=50 \quad \%$ & $\mathbf{N}$ & $\%$ & \\
\hline Dyspepsia & $30 \quad 60 \%$ & $52 \%$ & 56 & $56 \%$ & $\begin{array}{c}>0.05 \\
\mathrm{NS}\end{array}$ \\
\hline Halitosis & $44 \%$ & $34 \%$ & 39 & $39 \%$ & $\begin{array}{c}<0.05 \\
\mathrm{~S} \\
\end{array}$ \\
\hline Abdominal distension & $80 \%$ & $80 \%$ & 80 & $80 \%$ & $\begin{array}{c}>0.05 \\
\mathrm{NS}\end{array}$ \\
\hline Nausea & $18 \%$ & $22 \%$ & 20 & $20 \%$ & $\begin{array}{c}>0.05 \\
N S\end{array}$ \\
\hline Vomiting & $16 \%$ & $18 \%$ & 17 & $17 \%$ & $\begin{array}{c}>0.05 \\
\mathrm{NS}\end{array}$ \\
\hline Abdominal pain & $20 \%$ & $16 \%$ & 18 & $18 \%$ & $\begin{array}{c}>0.05 \\
\mathrm{NS}\end{array}$ \\
\hline Heart burn & $36 \%$ & $24 \%$ & 30 & $30 \%$ & $\begin{array}{c}<0.05 \\
\mathrm{~S}\end{array}$ \\
\hline Dysphagia & $18 \%$ & $14 \%$ & 16 & $16 \%$ & $\begin{array}{c}>0.05 \\
\mathrm{NS}\end{array}$ \\
\hline
\end{tabular}

NS = not significant.

$\mathrm{S}=$ significant.

There is a significant difference between hepatic encephalopathy group and non-hepatic encephalopathy group as regarding (halitosis and heartburn) while no significant difference as regarding the other symptoms. 
Table (3): Clinical picture: (Signs) of the studied groups

\begin{tabular}{|c|c|c|c|c|c|c|c|}
\hline \multirow{2}{*}{ Item } & \multicolumn{2}{|c|}{ HE group (A) } & \multicolumn{2}{|c|}{ Non-HE group (B) } & \multicolumn{2}{|c|}{ Total } & \multirow{2}{*}{ P.Value } \\
\hline & $\mathrm{N}=\mathbf{5 0}$ & $\%$ & $\mathrm{~N}=\mathbf{5 0}$ & $\%$ & $\mathbf{N}$ & $\%$ & \\
\hline Pallor & 18 & $36 \%$ & 16 & $32 \%$ & 34 & $34 \%$ & \multirow{9}{*}{$\begin{array}{c}>0.05 \\
\text { Not } \\
\text { significant }\end{array}$} \\
\hline Jaundice & 30 & $60 \%$ & 27 & $54 \%$ & 57 & $57 \%$ & \\
\hline Lower limb oedema & 40 & $80 \%$ & 35 & $70 \%$ & 75 & $75 \%$ & \\
\hline Splenomegaly & 41 & $82 \%$ & 37 & $74 \%$ & 78 & $78 \%$ & \\
\hline Ascites & 33 & $66 \%$ & 36 & $72 \%$ & 69 & $69 \%$ & \\
\hline Spider nevie & 30 & $60 \%$ & 32 & $64 \%$ & 62 & $\overline{62 \%}$ & \\
\hline Palmer erytrhema & 28 & $56 \%$ & 22 & $44 \%$ & 50 & $50 \%$ & \\
\hline Ecchymotic patches & 33 & $66 \%$ & 31 & $62 \%$ & 64 & $64 \%$ & \\
\hline Clubbing & 25 & $50 \%$ & 25 & $50 \%$ & 50 & $\overline{50 \%}$ & \\
\hline
\end{tabular}

There is no significant difference between hepatic encephalopathy group and non-hepatic encephalopathy group as regarding signs (pallor, jaundice, lower limb oedema, splenomegaly, etc...)

Table (4): Abdominal ultrasound findings in the studied groups

\begin{tabular}{|c|c|c|c|c|c|c|c|}
\hline \multirow{2}{*}{ Item } & \multicolumn{2}{|c|}{ HE group (A) } & \multicolumn{2}{|c|}{$\begin{array}{c}\text { Non-HE group } \\
\text { (B) }\end{array}$} & \multicolumn{2}{|c|}{ Total } & \multirow{2}{*}{ P Value } \\
\hline & $\mathbf{N}=\mathbf{5 0}$ & $\%$ & $\mathbf{N}=\mathbf{5 0}$ & $\%$ & $\mathbf{N}$ & $\%$ & \\
\hline \multicolumn{7}{|l|}{ Liver Size: } & \multirow{14}{*}{$\begin{array}{c}>0.05 \\
\text { Not } \\
\text { significant }\end{array}$} \\
\hline Average & 9 & $18 \%$ & 11 & $22 \%$ & 20 & $20 \%$ & \\
\hline Enlarged & 5 & $10 \%$ & 8 & $16 \%$ & 13 & $13 \%$ & \\
\hline Shrunken & 36 & $72 \%$ & 31 & $62 \%$ & 67 & $67 \%$ & \\
\hline Portal Vein thrombosis & 7 & $14 \%$ & 6 & $12 \%$ & 13 & $13 \%$ & \\
\hline \multicolumn{7}{|l|}{ Echopattern: } & \\
\hline$\overline{\text { Homogenous }}$ & 0 & $0 \%$ & 0 & $0 \%$ & 0 & $0 \%$ & \\
\hline Bright & 27 & $54 \%$ & 34 & $68 \%$ & 61 & $61 \%$ & \\
\hline Cirrhotic & 50 & $100 \%$ & 50 & $100 \%$ & 100 & $100 \%$ & \\
\hline $\begin{array}{l}\text { Liver surface: } \\
\text { Irregular }\end{array}$ & 50 & $100 \%$ & 50 & $100 \%$ & 100 & $100 \%$ & \\
\hline Spleen: & & & & & & & \\
\hline Average & 7 & $14 \%$ & 12 & $24 \%$ & 19 & $19 \%$ & \\
\hline Enlarged & 43 & $86 \%$ & 38 & $76 \%$ & 81 & $81 \%$ & \\
\hline Ascites: & 35 & $70 \%$ & 38 & $76 \%$ & 73 & $73 \%$ & \\
\hline
\end{tabular}

A non-significant difference was noticed between HE group and non-HE groupas regardabdominal ultrasound findings (Liver Size, echo pattern, surface, etc........) 
Table (5): Biochemical profile of the studied groups

\begin{tabular}{|l|c|c|c|}
\multicolumn{1}{|c|}{ Item } & $\begin{array}{c}\text { HE group(A) } \\
\mathbf{N = 5 0}\end{array}$ & $\begin{array}{c}\text { Non-HE group(B) } \\
\mathbf{N = 5 0}\end{array}$ & \multirow{2}{*}{ P. value } \\
\hline Total bilirubin & $2.3 \pm 1.3$ & $1.6 \pm 0.9$ & \multirow{2}{*}{$<0.05(\mathbf{S})$} \\
\hline ALT & $61 \pm 23.2$ & $51.24 \pm 21.8$ & \multirow{2}{*}{$>\mathbf{0 . 0 5}(\mathbf{N S})$} \\
\hline AST & $59.4 \pm 19.2$ & $50.3 \pm 18.2$ & \\
\hline Albumin & $2.45 \pm 0.6$ & $3.86 \pm 0.35$ & \\
\hline Prothrombin concentration & $67.3 \% \pm 6$ & $72.1 \% \pm 3.8$ & \\
\hline
\end{tabular}

$\checkmark \quad$ NS =not significant. $\quad$ S $=$ significant

- Total bilirubin was significantly higher in hepatic encephalopathy group than non HE group.

- $\quad$ ALT and AST were not significantly high in HE group as compared with non HE group

- Albumin was not significantly lower in HE group than non HE group

- Prothrombin concentration was not significantly lower in HE group than non HE group

Table (6): $H$. pylori stool antigen results in patients with liver cirrhosis with and without hepatic encephalopathy

\begin{tabular}{|c|c|c|c|c|c|c|c|}
\hline \multirow{2}{*}{ Item } & \multicolumn{2}{|c|}{ HE group (A) } & \multicolumn{2}{|c|}{ Non-HE group (B) } & \multicolumn{2}{|c|}{ Total } & \multirow{2}{*}{$P$ value } \\
\hline & $\mathbf{N}=50$ & & $\mathrm{~N}=\mathbf{5 0}$ & $\%$ & $\mathbf{N}$ & $\%$ & \\
\hline H. pylori positive & & $80 \%$ & 30 & $60 \%$ & 70 & $70 \%$ & $\begin{array}{c}<0.05 \\
\text { Significant }\end{array}$ \\
\hline H. pylori negative & & $20 \%$ & 20 & $40 \%$ & 30 & $30 \%$ & $\begin{array}{c}<0.05 \\
\text { Significant }\end{array}$ \\
\hline
\end{tabular}

Prevalence of $H$. pylori infection in the studied groups (patients of liver cirrhosis with and without hepatic encephalopathy) was 70\%, (liver cirrhosis with hepatic encephalopathy was $80 \%$ and liver cirrhosis without hepatic encephalopathy was $60 \%$ ) i.e. prevalence of $H$. pylori infection is significantly high in HE group than non HE group (P Value < 0.05$)$

Table (7): Correlation between H.pylori prevalance and hepatic encephalopathy grading.

\begin{tabular}{|c|c|c|c|c|c|}
\hline Grading & Number & $\%$ & H. pylori +ve & $\%$ & P. value \\
\hline Grade I & 14 & $28 \%$ & 9 & $64 \%$ & \multirow{5}{*}{$\begin{array}{c}<0.05 \\
\text { Significant }\end{array}$} \\
\hline Grade II & 14 & $28 \%$ & 11 & $8 \%$ & \\
\hline Grade III & 12 & $24 \%$ & 11 & $91 \%$ & \\
\hline Grade IV & 10 & $20 \%$ & 9 & $90 \%$ & \\
\hline Total & 50 & $100 \%$ & 40 & $80 \%$ & \\
\hline
\end{tabular}

Prevalence of $H$. pylori was higher in grade III more than other grades i.e. $64 \%$ of grade I were positive, $78 \%$ of grade II were positive, $91 \%$ of grade III were positive and $90 \%$ of grade IV were positive.

Prevalence of $H$. pylori was found significantly increasing with the severity of hepatic encephalopathy (Graph 2). 
Table (8): Results of ammonia level in patients of liver cirrhosis with and without hepatic encephalopathy

\begin{tabular}{|l|c|c|c|}
\hline \multicolumn{1}{|c|}{ Item } & $\begin{array}{c}\text { HE group (A) } \\
\mathbf{N = 5 0}\end{array}$ & $\begin{array}{c}\text { Non-HE group (B) } \\
\mathbf{N = 5 0}\end{array}$ & P value \\
\hline $\begin{array}{l}\text { Ammonia level } \\
\text { mmol/1 }\end{array}$ & $82.14 \pm 47.9$ & $36.44 \pm 17.9$ & $\begin{array}{c}<0.05 \\
\text { Significant }\end{array}$ \\
\hline
\end{tabular}

The normal range is $15-45 \mathrm{moml} / \mathrm{l}$, there is significant increase of blood ammonia level in hepatic encephalopathy group $82.14 \pm 47.9 \mathrm{moml} / \mathrm{l}$, as compared with non hepatic encephalopathy group $36.44 \pm 17.9$ as described in Table 9.

The blood ammonia level was significantly increased in HE group than non- HE group ( $\mathrm{P}$ value was $<0.05$ Significant).

Table (9): Relation between blood ammonia level and different grades of hepatic encephalopathy.

\begin{tabular}{|l|cc|c|c|}
\hline \multicolumn{1}{|c|}{ Grading } & Number & \% & Ammonia level & P.value \\
\hline Grade I & 14 & $28 \%$ & $80.40 \pm 5.63$ & \multirow{2}{*}{$<0.05$} \\
Grade II & 14 & $28 \%$ & $84.35 \pm 3.2$ & Significant \\
\hline Grade III & 12 & $24 \%$ & $87 \pm 3.9$ & \\
\hline Grade IV & 10 & $20 \%$ & $91 \pm 2.8$ & \\
\hline
\end{tabular}

There is asignificantly rising blood ammonia level in hepatic encephalopathy group with increasing the grade of hepatic encephalopathy, It was $80.40 \pm 5.63 \mathrm{moml} / \mathrm{l}$ in grade I hepatic encephalopathy patients, $84.35 \pm 3.2$ $\mathrm{moml} / 1$ in gradeII hepatic encephalopathy patients, $87 \pm 3.9 \mathrm{moml} / \mathrm{l}$ in grade III hepatic encephalopathy and $91 \pm 2.8 \mathrm{moml} / \mathrm{l}$ in grade IV hepatic encephalopathy patients ( Graph 3).

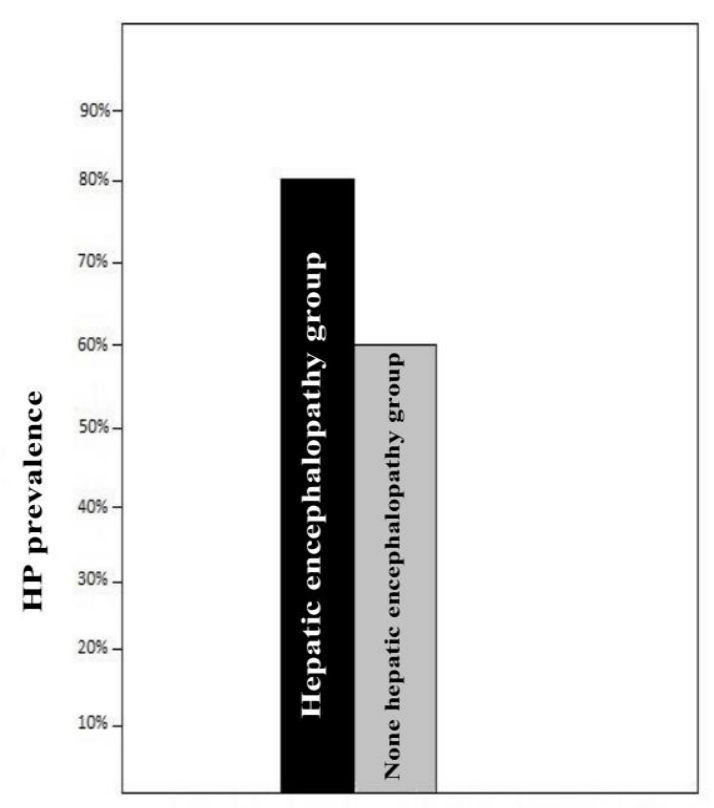

Figure (1): H. pylori prevalence in patients of liver cirrhosis with and without hepatic encephalopathy 


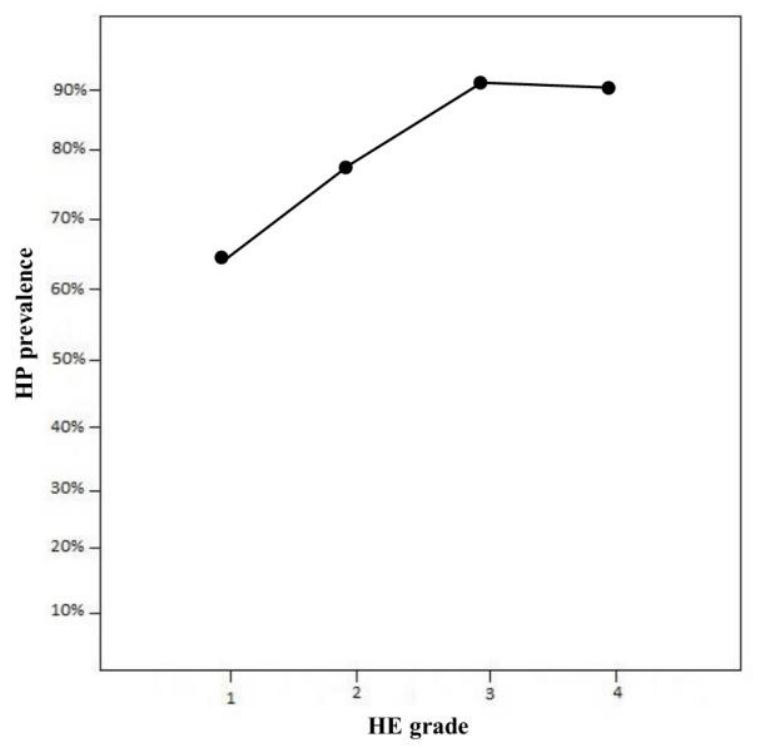

Figure (2): Correlation between H.pylori prevalence and hepatic encephalopathy grades

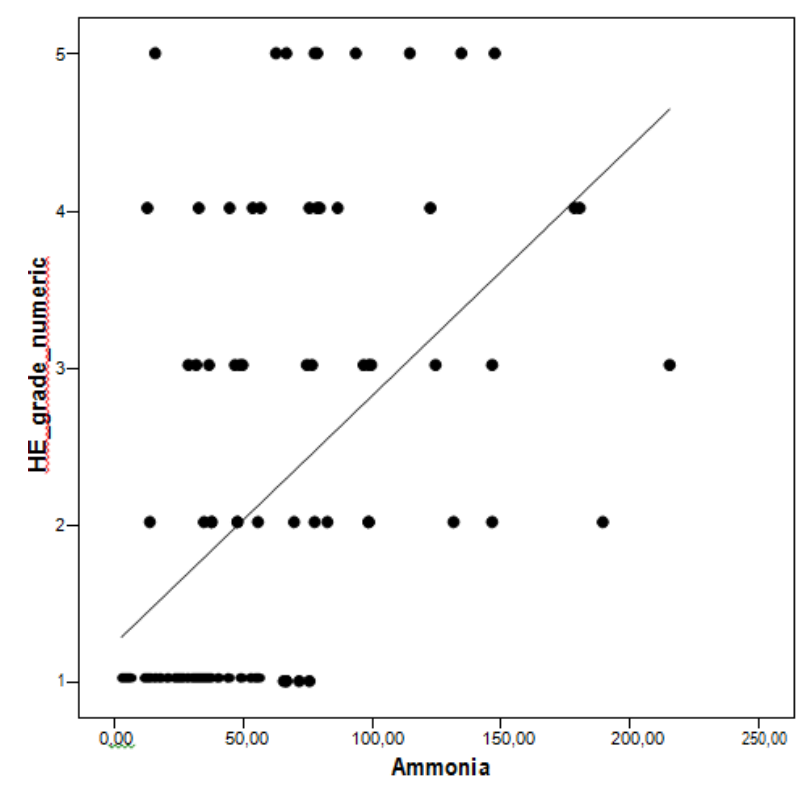

Figure (3): Correlation between hepatic encephalopathy grades and blood Ammonia level 


\section{DISCUSSION}

Hepatic encephalopathy represents a reversible decrease in neurologic function linked to cirrhosis by several mechanisms; the explanation of which still remains to be fully elucidated [12].

One of the initial hypotheses advanced to explain hepatic encephalopathy pointed to a key role for nitrogenous by-products of protein breakdown absorbed from the colon and reversed into portal circulation. In the setting of portosystemic shunting, portal blood flow is diverted away from the liver into the vena cava, and hepatic encephalopathy could be due to the cytotoxic effect of ammonia, a key intermediatein nitrogen and protein metabolism produced by the normal intestinal bacterial flora [13].

In cirrhotic patients, $H$. pylori infection is associated with hepatic encephalopathy, especially in younger patients with decompensated liver disease [13].

Gastric Helicobacter pylori infection is believed to be associated with a higher risk of hepatic encephalopathy among patients with cirrhosis of liver [14].

H. pylori is known to possess a urease activity, and therefore, might be an important source for ammonia production. Hepatic encephalopathy, in certain settings, could deteriorate due to this enhanced amount of ammonia [15].

Infectious diseases are now being implicated frequently as the cause of diseases that have been considered previously to be of non-infectious aetiology. Infection by $H$. pylori is one of them [16].

H. pylori is also associated with coronary artery disease, cerebrovascular disease, growth retardation in children, and Raynaud's phenomenon [17].

The role of $H$. pylori as a cause of hyperammonaemia in patients with liver cirrhosis has still not been fully clarified [18].Few studies have investigated this issue and found that $H$. pylori infection was significantly more frequent in patients with encephalopathy than without [13].

In an interventional study, Zullo, et al. revealed a decrease in ammonia levels in patients treated by hydroxamic acid, an inhibitor of bacterial urease, while no changes were reported in the noninfected patients [19]. However, in a different situation, these were not confirmed by Vasconez et al. [16].

Siringo et al. reported a very high prevalence of $H$. pylori infection in cirrhotics, compared with blood donors $(\mathrm{p}<0.0005)$ in Italy [20].

In our study, we observed a significantly high prevalence of $H$. pylori among the hepatic patients with or without hepatic encephalopathy with higher prevalence in hepatic encephalopathy group (A) (80\% positive), than non-hepatic encephalopathy group (B) $(60 \%$ positive). Fan et al. found a higher seroprevalence of $H$. pylori in Chinese hepatic patients than in controls matched for age and socioeconomic status. The study was performed on 360 hepatic patients and 100 controls, the result was $72 \%$ seropositive in hepatic patients and 39\% seropositive in control group [21].

In our study, there was a significantly higher prevalence of $\mathrm{H}$. pylori and blood ammonia levels among the hepatic encephalopathy group (A) than non hepatic encephalopathy group (B). Prevalence of $\mathrm{H}$. pylori was $80 \%$ positive in hepatic encephalopathy group (A) and $60 \%$ positive in non hepatic encephalopathy group (B), and mean blood ammonia levels were: $82.14 \pm 47.9$ $\mathrm{mmol} / \mathrm{l}$ for group A (liver cirrhosis with hepatic encephalopathy), and $36.44 \pm 17.9 \mathrm{mmol} / \mathrm{l}$ for group B (liver cirrhosis without hepatic encephalopathy). Our results were nearly similar to the results of Fan, in china which was $78 \%$ in hepatic encephalopathy group and 56\% in hepatic patients without hepatic encephalopathy [21].

Sethar et al. reported that the frequency of $H$. pylori antibodies in patients presenting with porto-systemic encephalopathy due to liver disease is higher than control group .Seventy-six patients of porto-systemic encephalopathy due to liver diseases were selected . They were evaluated for hepatic encephalopathy grade, out of 76 patients who presented with porto-systemic encephalopathy, $59(77.6 \%)$ had a positive $\mathrm{H}$. pylori antibody test [22].

A study performed by $\mathrm{Si} \mathrm{J}$ et al. in China to determine whether liver cirrhosis associated with $H$. pylori infection will induce increased serum ammonia. The mean levels of serum ammonia in the cirrhotic group with $H$. pylori infection were $142.2+/-13.35 \mathrm{mmol} / \mathrm{L}$. They were increased significantly as compared with cirrhotic patients without $H$. pylori infection $(37.23+/-7.04$ $\mathrm{mmol} / \mathrm{L}$ ), so $H$. pylori infection can induce an 
increase in serum ammonia in patients with liver dysfunction [23].

The results of our study are in agreement with their results, as there was a positive correlation between prevalence of $H$. pylori and hepatic encephalopathy. As well as prevalence of $H$. pylori and blood ammonia levels were found significantly increasing with the severity and degree of hepatic encephalopathy, which suggests that $H$. pylori infection may have a role in the pathogenesis of hepatic encephalopathy.

These findings do not correlate with the results of Guillermo et al. In their study they found $\mathrm{H}$. pylori seropositivity in hepatic encephalopathy grade I $(77.63 \%)$, grade II $(78.13 \%)$, grade III (100\%), grade IV (75\%) [24].

In a study performed by Yang et al., three hundred and sixty-eight cirrhotic patients were enrolled. They observed that $H$. pylori infection aggravates the blood ammonia concentration and hepatic encephalopathy in cirrhotic patients. This study correlates with our study where there was a positive correlation between prevalence of $H$. pylori and hepatic encephalopathy [25].

A systemic review performed by Bang-Li Hu et al. surveyed twenty studies that explored the role of $H$. pylori in HE pathogenesis, eleven of which evidenced that the prevalence of H.pylori is higher in HE patients, while the evidence of nine studies failed to find that blood ammonia level was higher in $H$. pylori positive cirrhotic patients than in negative patients [26].

Chakrabarti et al. found no significant correlation between gastric juice ammonia concentrations and arterial ammonia levels in the study of 66 hepatic patients. The data suggest that liver impairment remains conclusive in ammonia disposal in patients with cirrhosis, whereas $H$. pylori infection does not seem to play a major role in the pathogenesis of hyperammonemia in these patients [27].

Also, in the study performed by Zullo et al. in Italy, who focused on the relationship between H. pylori, plasma ammonia levels, and intellectual function in cirrhotic patients. Forty-seven cirrhotics with latent or mild hepatic encephalopathy were enrolled in the study. This study failed to find a relationship between $H$. pylori, plasma ammonia levels, and psychometric testing scores in cirrhotic patients with latent or mild hepatic encephalopathy [28].
The reduction in blood ammonia levels after $H$. pylori eradication found in some studies has been attributed to a nonspecific effect of antibiotic therapy on ammonia producing gut flora rather than $H$. pylori eradication [29].

\section{CONCLUSION}

In conclusion; although colonic bacteria are considered to be the main source of ammonia and the major pathogenic factor for hepatic encephalopathy, $H$. pylori may be an important co-factor for pathogenicity of hepatic encephalopathy, based on being more prevalent in patients with chronic liver disease especially with hepatic encephalopathy.

Ethical approval: Approved.

Funding: None.

\section{Conflict of interest: None.}

\section{REFERENCES}

1. Friedman LS., Mc Phee SJ., Papadakis MA., Gonzalez R., Zeiger R. Liver, Biliary Tract and Pancreas Disorders.In Current Medical Diagnosis and Treatment, 49th ed. Mc Graw Hill Lange 2010; 598-648.

2. Bacon BR., Fauci AS., Braunwald E., Kasper DL., Hauser SL., Longo DL., et al., eds. Cirrhosis and its complications. In: Harrison's Principles of Internal Medicine17th ed. NewYork, Mc Graw Hill 2008.

3. Chapman RW., Collier JD., Hayes PC., Boon NA., Colledge NR., Walker BR., et al., eds. Liver and Biliary Tract Diseases. In: Davidson's Principles and Practice of Medicine 20th ed. Chirch ill Livingstone Elsevier Ltd. 2006; 935-98.

4. Zullo A., Hassan C., Morini S. Hepatic encephalopathy and Helicobacter pylori:a critical reappraisal.J Clin Gastroenterol 2003; 37:164-68.

5. Queiroz DM., Rocha AM., Rocha GA., Cinque SM.,Oliveira AG., Godoy A., Tanno H. Association between Helicobacter pylori infection and cirrhosis inpatients with chronic hepatitis $\mathrm{C}$ virus. Dig Dis Sci2006; 51: 370-73.

6. Nandakumar R., Naik AS., Pandit B., Kamat R., Bhatia SJ. Effect of Helicobacter pylori eradication on serum ammonia levels in patients with chronic liver disease. Indian J Gastroenterol 2003; 22:22123.

7. Abdel-Hady H., Zaki A., Badra G., Lotfy M., Selmi C., Giorgini A. et al. Helicobacter pylori infection in hepatic encephalopathy: Relationship to plasma endotoxins and blood ammonia. Hepatol Res 2007; 37: 1026-33. 
8. Udayakumar N., Subramaniam K., Umashankar L, Verghese J., Jayanthi V. Predictors of mortality in hepatic encephalopathy in acute and chronic liverdisease:a preliminary observation. J Clin Gastroenterol 2007; 41: 922-26.

9. Seckin Y., Harputluoglu MM., Batcioglu K., Karincaoglu M., Yildirim B., Oner RI., et al. Gastric tissue oxidative changes in portal hypertension and cirrhosis. Dig Dis Sci 2007; 52: 1154-58

10. Als-Nielsen B, Gluud LL, Gluud C. Nonabsorbable disaccharides for hepatic encephalopathy: systematic review of randomised trials. $B M J$ 2004; 328(7447): 1046.

11. Korkmaz H, Kesli R, Karabagli P, Terzi Y. Comparison of the diagnostic accuracy of five different stool antigen tests for the diagnosis of Helicobacter pylori infection. Helicobacter 2013; 18:384-391.

12. CalvetX,QuesadaM,SanfeliuI,SalcedaF,Rosello M, MontserratA, et al. Diagnosis of $\mathrm{H}$. pylori in dyspeptic patients by stool antigen detection usefulness of a new monoclonal enzyme immunoassay test. Diag. Liver Dis2004; 36:4504.

13. Dasani BM, Sigal SH, Lieber CS. Analysis of risk factors for chronic hepatic encephalopathy : the role of H. pylori infection. Clin. Gastroenterol 1998; 45:423-7.

14. Kini D, Aggarwal R, Saraswat VA, Naik SR.Role of $H$. pylori infection in hyperammonemia and subclinical hepatic encephalopathy in cirrhosis of liver.Gastroenterol and Hepatol 2001; 34: 3231.

15. Zullo A, Hassan C, Cristofari F, Andriani A, De Francesco V, Ierardi E et al: Effects of Helicobacter pylori eradication on early stage gastric mucosa-associated lymphoid tissue lymphoma. Clin Gastroenterol Hepatol. 2010, 8:105-110.

16. Vasconez C ,Elizolde JI, Lioch J, Ginès A, de la Rosa C, Fernández RM et al. H.pylori hyperammonemia and subclinical portosystemic encephalopathy-effects of eradication.J Hepatol 1999; 30(2):260-4.

17. Ponzetto A, Pellicano R, Leon N, Cutufia MA, Turini F , Grigioni WF et al, H. pylori infection and cirrhosis in hepatitis $\mathrm{C}$ virus carriage: is itan innocent bystander or a troublemaker? Am J Gastroenter 2000 ;54:275-7.

18. Attili AF. Helicobacter pylori infection, plasma ammonia levels, and psychometric testing in cirrhotic patients. Gastroenterol and Hepatol J 1994; 14:234-9.
19. Zullo A, Rinaldi V, Hassan C, Folino S, Winn S, Pinto G, Attili AF. Helicobacter pylori and plasma ammonia levels in cirrhotics: role of urease inhibition by acetohydroxamic acid.Ital $J$ Gastroenterol Hepatol. 1998 , 30(4):405-9.

20. Siringo S, Vaira D, Menegatti M, Piscaglia F, Sofia S, Gaetani M, et al. High prevalence of Helicobacter pylori in livercirrhosis: relationship with clinical and endoscopic features and the risk of peptic ulcer. Dig Dis Sci. 1997; 42(10):2024-30.

21. Fan XG, Zou YY, Wu AH, Li TG, Hu GL, Zhang Z. Seroprevalenceof Helicobacter pylori infection in patients with hepatitisB. Br J BiomedSci 1998;55:176-8.

22. Sethar GH, Ahmed R, Zuberi BF, Afsar S. Frequency of Helicobacter pylori antibodies in porto-systemic encephalopathy. $J$ Coll. Physicians Surg Pak. 2004, 14(9):530-3.

23. Si J, Cao Q, Gao M, Fang L, Qian G, Wang Y.Chin Med J (Engl); 2000,113(12):1080-1.

24. Guillermo H, Zullo A, Lucey MR. Association between $H$. pylori infection and subclinical hepatic encephalopathy AmJ; 1993, (3):232-3.

25. Yang CS, Cao SY, He XJ, Wang YX, Zhang YL. Study of correlation between Helicobacter pylori infection and hyperammonemia and hepatic encephalopathy in cirrhotic patients. Chinese critical care medicine. 2007, 19(7):422-4.

26. Hu BL, Wang HY, Yang GY. Association of Helicobacter pylori infection with hepatic encephalopathy risk: A systematic review. Clin Res Hepato Gastroenterol 2013; 37(6): 619-625

27. Chakrabarti P, Zullo A, Hassan C, Pandit A, Chowdhury A, Santra A et al. H. pylori, gastric Juice and arterial ammonia levels in patients with cirrhosis. Br. Gastroenterl 2002; (4):54:455-2.

28. Zullo A, Rinaldi V, Meddi P, Winn S, Moscatelli R, Attili AF. Helicobacter pylori eradication with dual and low-dose triple therapy in patients with liver cirrhosis. Ital J Gastroenterol Hepatol. 1999; (9):831-5.

29. Qin SY, Jiang HX, Ning HJ, Nie HM, Tao L, Hu BL, et al. Effect of Helicobacter pylori eradication on blood ammonia levels in cirrhotic patients: a systematic review. Hepatogastroenterology 2012;59(120):2576-81.

Peer reviewer: Tarik Zaher, Professor of Tropical Medicine and Hepatogastroenterology, Faculty of Medicine, Zagazig University, Egypt.

Editor: Mohamad Emara, Lecturer of Tropical Medicine and Hepatogastroenterology, Faculty of Medicine, Zagazig University, Egypt 30 . 